\title{
Advanced 3D nanohybrid foam based on graphene oxide: Facile fabrication strategy, interfacial synergetic mechanism, and excellent photocatalytic performance
}

\author{
Xiaoyuan Zhang ${ }^{1 \dagger}$, Wenfeng $\mathrm{Wei}^{1 \dagger}$, Shan Zhang ${ }^{1}$, Bianying Wen ${ }^{2^{*}}$ and Zhiqiang $\mathrm{Su}^{1^{*}}$
}

\begin{abstract}
Herein, a unique nanohybrid foam was fabricated with titanium dioxide $\left(\mathrm{TiO}_{2}\right)$-carbon quantum dots (CQDs) nanoparticles intercalated between graphene oxide (GO) layers via a facile and low-cost solvothermal method. Compared with pure GO foam, the fabricated $\mathrm{GO}^{-\mathrm{TiO}_{2}-\mathrm{CQDs}}$ foam displayed high degradation rate towards methyl orange (MO), methylene blue (MB), and rhodamine $\mathrm{B}$ (RhB), respectively, under the Xenon lamp irradiation. The composite foam can be used for several times and remain a high degradation rate without structural damage. The photochemical property was attributed to the $3 \mathrm{D}$ porous structure of GO$\mathrm{TiO}_{2}-\mathrm{CQDs}$ foam, in which ultrafine hydrogenated $\mathrm{TiO}_{2}-$ CQDs nanoparticles were densely anchored on the GO sheets. This paper provides an efficient strategy to tune the charge transport and thus enhance the photocatalytic performance by combining the semi-conductive GO and quantum dots.
\end{abstract}

Keywords: graphene, titanium dioxide, carbon quantum dots, nanohybrid foam, photocatalytic degradation

\section{INTRODUCTION}

With the increasing environmental contamination over recent years, photocatalyst materials have attracted much attention due to their controllable and adjustable properties. Photocatalysis is a simple process to degrade water pollution with high reactivity by photocatalysts under mild reaction conditions. Photocatalysts can convert light into chemical energy, thus promoting the oxidization or reduction of the pollutants $[1,2]$. The primary requirement for the photocatalysts is that there is sufficient energy to induce a catalytic chemical reaction. Among all the photocatalysts, metal oxide semiconductors such as zinc oxide $\left(\mathrm{ZnO}, E_{\mathrm{g}}=3.2 \mathrm{eV}\right)$ [3,4], ferric oxide $\left(\mathrm{Fe}_{2} \mathrm{O}_{3}, E_{\mathrm{g}}\right.$ $=3.2 \mathrm{eV})$ [5], titanium dioxide $\left(\mathrm{TiO}_{2}, E_{\mathrm{g}}=3.2 \mathrm{eV}\right)$ [6], cuprous oxide $\left(\mathrm{Cu}_{2} \mathrm{O}, E_{\mathrm{g}}=2.2 \mathrm{eV}\right)$ [7-9], and tin oxide $\left(\mathrm{Sn}_{2} \mathrm{O}_{3}, E_{\mathrm{g}}=3 \mathrm{eV}\right)[10,11]$ are recognized as the efficient degraders for organic dyes. The photo-generated electrons and holes from the photocatalysts can interact with the surrounding environment to produce superoxide radicals or hydroxyl radicals. These radicals have strong oxidative properties and can degrade pollutants in water. These metal oxides have been widely investigated for photocatalysis [7], Li-ion battery [12], and supercapacitors [13], due to their large specific surface area and excellent electrochemical activity.

The cost-effective $\mathrm{TiO}_{2}$ is an outstanding candidate for the photocatalyst owing to its superior properties, including chemical stability, durable oxidizing power, and nontoxicity [14]. Zhang et al. [15] fabricated a waterdispersible $\mathrm{TiO}_{2}$ /graphene nanocomposite via a facile and efficient hydrothermal approach. $\mathrm{TiO}_{2}$ can generate highly active electrons and holes to react with oxygen in water, and further degrade organic dyes in water. It was noticed that the architectures of the $\mathrm{TiO}_{2}$, including nanosphere [16], nanotube [17], nanowire [18], and nanosheet [19], influence the physicochemical properties of

\footnotetext{
${ }^{1}$ State Key Laboratory of Chemical Resource Engineering, Beijing Key Laboratory of Advanced Functional Polymer Composites, Beijing University of Chemical Technology, Beijing 100029, China

${ }^{2}$ Beijing Key Laboratory of Quality Evaluation Technology for Hygiene and Safety of Plastics, Beijing Technology and Business University, Beijing 100048, China

$\dagger$ These authors contributed equally to this work.

* Corresponding authors (emails: suzq@mail.buct.edu.cn (Su Z); wenbianying@tsinghua.org.cn (Wen B))
} 
the photocatalysts. Reports showed that combining $\mathrm{TiO}_{2}$ with other semiconductor nanomaterials could effectively improve the photocatalysis via the interfacial chargetransfer processes of the photo-generated charge carriers [6]. Notably, conductive carbonaceous materials, such as graphene and carbon quantum dot (CQD), were integrated with $\mathrm{TiO}_{2}$ to adjust the band gap and enhance the charge transfer rate of the nanocomposites [20,21]. Sathish Kumar et al. [22] obtained $\mathrm{CQD} / \mathrm{TiO}_{2}$ nanohybrids via a simple one-step solvothermal method. The $\mathrm{CQD} / \mathrm{TiO}_{2}$ exhibited high decomposition rate of methylene blue $(\mathrm{MB})$, due to the fast charge transfer between CQD and $\mathrm{TiO}_{2}$. CQDs can promote the interfacial charge, energy transfer, and relaxation processes, and thus enhance the photocatalytic performance of $\mathrm{TiO}_{2}$. Other than CQDs, graphene exhibits sizeable specific surface area and excellent electrical conductivity. Yang et al. [23] fabricated $\mathrm{TiO}_{2}$ with different dimensions by in-situ synthetic strategies and then hybrided them with graphene. Graphene plays a substantial role in collecting photoexcited electrons from the conduction band of $\mathrm{TiO}_{2}$ and prevents the recombination of electrons and holes generated inside or on the surface of the $\mathrm{TiO}_{2}$ [7]. Different constructions of nanocomposites expand the scope of photocatalysis [24-26]. Lee et al. [27] demonstrated that graphene wrapped amorphous $\mathrm{TiO}_{2}$ nanoparticles possessed excellent photocatalytic properties under visible light for the degradation of MB.

In this study, the three-dimensional (3D) hybrid foam composed of $\mathrm{TiO}_{2}$-CQDs nanoparticles and graphene oxide (GO) nanosheets was fabricated via the hydrothermal method as shown in Scheme 1. Compared with powders and membranes of graphene and $\mathrm{TiO}_{2}$ nanocomposites, 3D graphene foam displays high elasticity and mechanical stability, excellent electrochemical stability, and high conductivity, due to the well interconnected porous microstructure in the nanocomposites, which benefit the adsorption of contaminant and the hybrid of electrodes [12,28-30]. Deng et al. [31] obtained GO sheets with different lateral sizes by controlling the delamination conditions of graphite oxide with a convenient one-step hydrothermal self-assembly method. In our system, graphene was utilized to integrate with $\mathrm{TiO}_{2}-$ CQDs nanoparticles and then form a 3D structure to promote efficient charge separation. This study provides a new opportunity for developing reusable and high-performance photocatalyst for wastewater treatment.

\section{EXPERIMENTAL SECTION}

\section{Materials}

Natural graphite flake (99.8\% purity) and glucose $(99.5 \%$ purity) were purchased from Sigma Aldrich. Potassium permanganate $\left(\mathrm{KMnO}_{4}\right)$ and absolute ethanol were purchased from Beijing Chemicals Co., Ltd (Beijing, China). Sulfuric acid $\left(\mathrm{H}_{2} \mathrm{SO}_{4}\right.$, analytical grade, $98 \%$ aqueous solution), phosphoric acid $\left(\mathrm{H}_{3} \mathrm{PO}_{4}\right.$, analytical grade, $35 \%$ aqueous solution), and hydrogen peroxide $\left(\mathrm{H}_{2} \mathrm{O}_{2}\right.$, analytical grade, $30 \%$ aqueous solution) were bought from Tianjin Dongfang Chemical Plant (Tianjin, China). $\mathrm{TiO}_{2}$ (analytical grade, P25), thiourea, rhodamine B (RhB), methyl orange (MO), and $\mathrm{MB}$ were purchased from J\&K (Beijing, China). All the chemicals were used without additional purification. The deionized water was obtained by a Millipore system $\left(\approx 18.2 \mathrm{M} \Omega \mathrm{cm}^{-1}\right)$.

\section{Preparation of $\mathrm{TiO}_{2}$-CQDs nanocomposites}

Firstly, CQDs were fabricated via a one-pot hydrothermal method [32]. In detail, $2 \mathrm{~g}$ glucose was dissolved in $20 \mathrm{~mL}$ deionized water. Then, the solution was transferred into a Teflon-lined stainless steel autoclave for hydrothermal reaction at $200^{\circ} \mathrm{C}$ for about $10 \mathrm{~h}$ to obtain the CQDs.

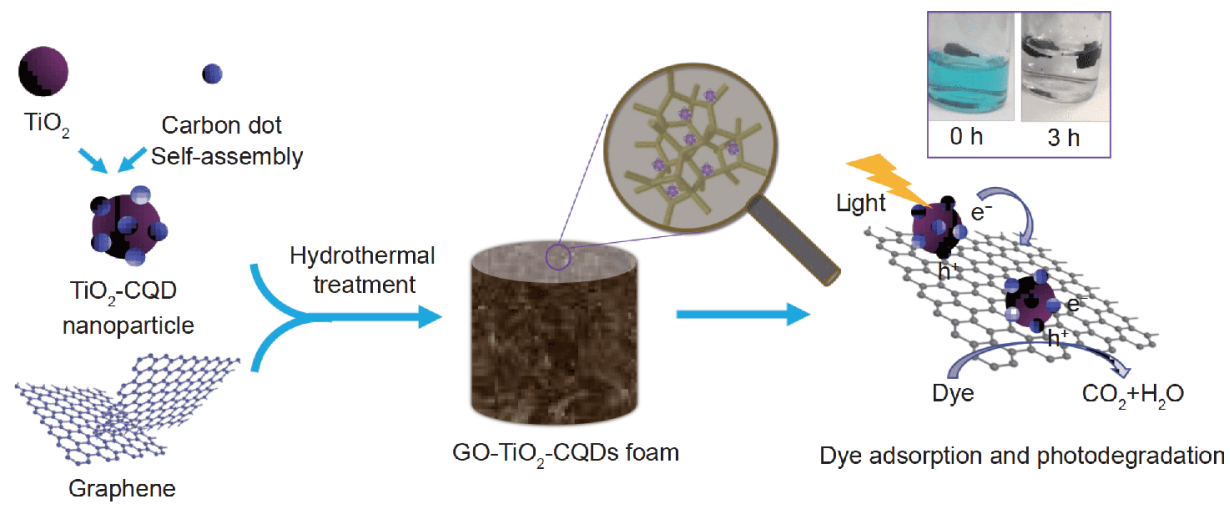

Scheme 1 Schematic of the preparation of $\mathrm{GO}-\mathrm{TiO}_{2}-\mathrm{CQD}$ foam. 
Then, the CQDs were anchored on the surfaces of $\mathrm{TiO}_{2}$ nanoparticles with a primary particle size of $25 \mathrm{~nm}$ by stirring $\mathrm{TiO}_{2}(100 \mathrm{mg})$ with a pre-determined amount of CQDs in $30 \mathrm{~mL}$ deionized water for $30 \mathrm{~min}$. The solution became a homogeneous light brown suspension without visible precipitation, and then was transferred into a Teflon-lined stainless steel autoclave for hydrothermal reaction about $10 \mathrm{~h}$ at $200^{\circ} \mathrm{C}$. Then, the solution was cooled at ambient temperature, and a dark brown liquid was obtained. The composites were isolated by centrifugation and dried under vacuum at $60^{\circ} \mathrm{C}$.

\section{Preparation of GO}

GO was synthesized according to the modified Hummers method [33]. Specifically, $40 \mathrm{~mL}$ concentrated phosphoric acid and $360 \mathrm{~mL}$ sulfuric acid were slowly injected into $3 \mathrm{~g}$ of natural graphite flakes under stirring at ambient temperature. Then $18 \mathrm{~g}$ potassium permanganate was added slowly into the system in the water bath for $12 \mathrm{~h}$ $\left(50^{\circ} \mathrm{C}\right)$. After cooled down to $25^{\circ} \mathrm{C}$, the mixture was slowly poured onto $200 \mathrm{~mL}$ ice crush and $5 \mathrm{~mL} 10 \%$ hydrogen peroxide. Then the luminous yellow solution was centrifuged for $30 \mathrm{~min}(4000 \mathrm{rpm})$. The precipitation was then washed with water, $30 \%$ hydrochloric, and ethanol $(2 \times)$, respectively. Subsequently, the obtained suspension was filtered through a polytetrafluoroethylene (PTFE) membrane (pore size: $0.22 \mu \mathrm{m}$ ) using diethyl ether as the solvent. After vacuum-drying for $12 \mathrm{~h}$, the GO was obtained.

\section{Preparation of $\mathrm{GO}^{-\mathrm{TiO}_{2}}$-CQD foam}

The $\mathrm{GO}-\mathrm{TiO}_{2}-\mathrm{CQDs}$ foam was fabricated by hydrothermal treatment. Firstly, $20 \mathrm{mg} \mathrm{TiO}_{2}$-CQD nanoparticles were dispersed in $30 \mathrm{~mL}$ homogeneous $\mathrm{GO}$ $\left(2 \mathrm{mg} \mathrm{mL}{ }^{-1}\right)$ suspension. After the addition of $1 \mathrm{~g}$ thiourea, the mixture was sonicated for $30 \mathrm{~min}$. Next, the mixture was transferred into a 50-mL Teflon-lined stainless steel autoclave and maintained at $180^{\circ} \mathrm{C}$ for $4.5 \mathrm{~h}$. After natural cooling, the $\mathrm{GO}-\mathrm{TiO}_{2}-\mathrm{CQD}$ foam was soaked in distilled water for $24 \mathrm{~h}$ along with three times of water change to remove residual gas and other impurities. Finally, vacuum freeze-drying was used to remove water and the $\mathrm{GO}-\mathrm{TiO}_{2}-\mathrm{CQD}$ foam was obtained. The preparation of pure graphene foam was to disperse GO into $30 \mathrm{~mL}$ suspension with the assistance of $1 \mathrm{~g}$ thiourea. After ultrasonic dispersion, the mixture was transferred into a 50-mL Teflon-lined stainless steel autoclave under the same hydrothermal conditions and operation steps. To obtain $\mathrm{GO}-\mathrm{TiO}_{2}$ foam, $1 \mathrm{~g}$ thiourea and $100 \mathrm{mg} \mathrm{TiO}{ }_{2}$ powder were dispersed into $30 \mathrm{~mL}$ suspension of GO.
After ultrasonic dispersion, the mixture was transferred into a 50-mL Teflon-lined stainless steel autoclave under the same hydrothermal conditions and operation steps.

\section{Photodegradation of organic dyes}

The photodegradation behaviors of the hybrids were measured with $\mathrm{MB}, \mathrm{RhB}$, and MO. They were mixed just before the degradation experiments. The foam $(15 \mathrm{mg})$ was immersed into $4.5 \mathrm{~mL} \mathrm{MB}, \mathrm{RhB}$, and $\mathrm{MO}$ solution $\left(10 \mu \mathrm{mol} \mathrm{L}^{-1}\right)$, respectively. Photocatalysis was carried out under the irradiation of the Xenon lamp of $150 \mathrm{~W}$. The absorbance of the reaction solution was monitored in real time, and each data was repeated for three times to get the average value. The foams after the dye absorption were soaked in $5 \mathrm{~mL}$ ethanol solution for desorption, and the absorbance of the solution was measured every half an hour. During the desorption process, the ethanol solution gradually changed from colorless to the color of the dye, until the color of the solution no longer varied, indicating that the dye was entirely desorbed and the foam can be reused.

\section{Characterization}

The scanning electron microscopy (SEM) images of the $\mathrm{TiO}_{2}$-CQDs nanoparticles and $\mathrm{GO}-\mathrm{TiO}_{2}-\mathrm{CQDs}$ foam were obtained by using the JSM-6700F (JEOL, Japan). The transmission electron microscopy (TEM) images were acquired on a JEM-2100F(JEOL, Japan) at the acceleration voltage of $200 \mathrm{kV}$. The $\mathrm{TiO}_{2}$-CQDs nanohybrids aqueous solution was dropped onto the copper grid and dried at room temperature. X-ray diffraction (XRD) was taken on a Rigaku D/max-2500 VB+/PC(JEOL, Japan) equipment with the scanning $2 \theta$ angle from $5^{\circ}$ to $90^{\circ}$. X-ray photoelectron spectroscopy (XPS) was performed on thermo VG (ESCALAB 250, Waltham, USA). Raman spectroscopy was recorded by a Raman spectroscope (LabRAM HORIBA JY, Edison, NJ). The solid powder and foam were placed directly on a quartz glass slide, and the laser focus position was adjusted before testing. Fourier transform infrared spectroscopy (FTIR) was recorded using a Nicolet NEXUS (Nicolet 6700, Thermo-Fisher, USA) instrument with transmission accessory. The atmospheric background was collected before each scan. The samples were prepared by potassium bromide $(\mathrm{KBr})$ tableting method. The samples of $\mathrm{TiO}_{2}-$ $\mathrm{CQD}$ and $\mathrm{GO}-\mathrm{TiO}_{2}-\mathrm{CQD}$ were ground uniformly with $\mathrm{KBr}$ according to the ratio of 1:100 in an agate mortar. And then they were tested by transmission plug. The concentration of dyes during the photodegradation was characterized by UV-vis (PerkinElmer, Lambda 365, 
Korea) absorbance measurement.

\section{RESULTS AND DISCUSSION}

\section{Morphology of GO-TiO $\mathrm{T}_{2}$-CQD foam}

The morphological changes of $\mathrm{TiO}_{2}-\mathrm{CQDs}$ nanoparticles were characterized by SEM, shown as the images of the $\mathrm{TiO}_{2}$ nanoparticles before and after CQD decoration, with $\mathrm{TiO}_{2} @ g l u c o s e$ as the reference to identify the function of CQD in the nanocomposite, and decrease the uncertainty from the addition of glucose. It can be found that the irregular nanoparticles formed when the $\mathrm{TiO}_{2}$ nanoparticles were directly mixed with glucose (Fig. 1a). However, after decorating the CQDs, the obtained $\mathrm{TiO}_{2}{ }^{-}$ CQDs display satellite structure with the surface nanoparticle size ranging from 50 to $100 \mathrm{~nm}$ (Fig. 1b, c).

Moreover, the CQDs on the surface of $\mathrm{TiO}_{2}$-CQDs reduced the aggregation and resulted in a better dispersion of $\mathrm{TiO}_{2}$. The $-\mathrm{OH}$ functional groups on the surface of the $\mathrm{TiO}_{2}$ can anchor on the surface of CQDs, leading to the satellite structure of $\mathrm{TiO}_{2}$-CQDs with the alternating arrangement of $\mathrm{TiO}_{2}$ and CQDs. As shown in Fig. 1d-e, the $\mathrm{TiO}_{2}$-CQDs contain only three elements, $\mathrm{C}, \mathrm{O}$, and $\mathrm{Ti}$, indicating that most of the surface elements are CQDs, and the content of Ti element is only $0.1 \%$.

The morphology of the prepared GO and $\mathrm{GO}-\mathrm{TiO}_{2}-$ CQDs foam was characterized and shown in Fig. 2a, b. It can be seen that GO foam is stacked by many lamellas with many uneven holes. The size of the hole can be adjusted based on the concentration of graphene. The internal hole is more uniform and has a relatively stable structure when the concentration of graphene is $2 \mathrm{mg} \mathrm{mL}{ }^{-1}$. The lower concentration of the original solution, the higher the specific surface area of the foam. However, the structure is loose, and the mechanical property is poor in hybrid foam with low graphene concentration. Therefore, the concentration of graphene in $2 \mathrm{mg} \mathrm{mL}^{-1}$ was selected for the subsequent experiments. In the hydrothermal preparation process of the foam, thiourea was decomposed into ammonia and hydrogen sulfide, which could further exfoliate GO into single layer and reduce GO. Besides, these compounds decorated on the surface of GO, so that the stacking between the adjacent layers became more compact via $\pi-\pi$ stacking, electrostatic interaction and hydrogen bonds. However, a larger content of thiourea will not lead to stable GO foam because of the gas molecules release. Therefore, $1.0 \mathrm{~g}$ thiourea was applied in the experiment. In Fig. $2 c, d$, the SEM images of $\mathrm{GO}-\mathrm{TiO}_{2}$-CQDs foam show that the addition of $\mathrm{TiO}_{2}$ does not affect the microporous structure of GO, but help to form aggregates at nanoscale, which significantly increases the specific area of foam. Also, we found the nanoparticles did not fall off even when they were immersed in deionized water for several days. This indicates that the $\mathrm{TiO}_{2}$-CQDs nanoparticles are successfully loaded on the graphene layers through electrostatic interaction and hydrogen bonds.

\section{Structural analysis of $\mathrm{GO}^{-\mathrm{TiO}_{2}}$-CQD foam}

The change of functional groups before and after the combination of $\mathrm{TiO}_{2}$ with CQDs was explored by UV-vis testing in Fig. 3a. The absorption band at $226 \mathrm{~nm}$ is as-
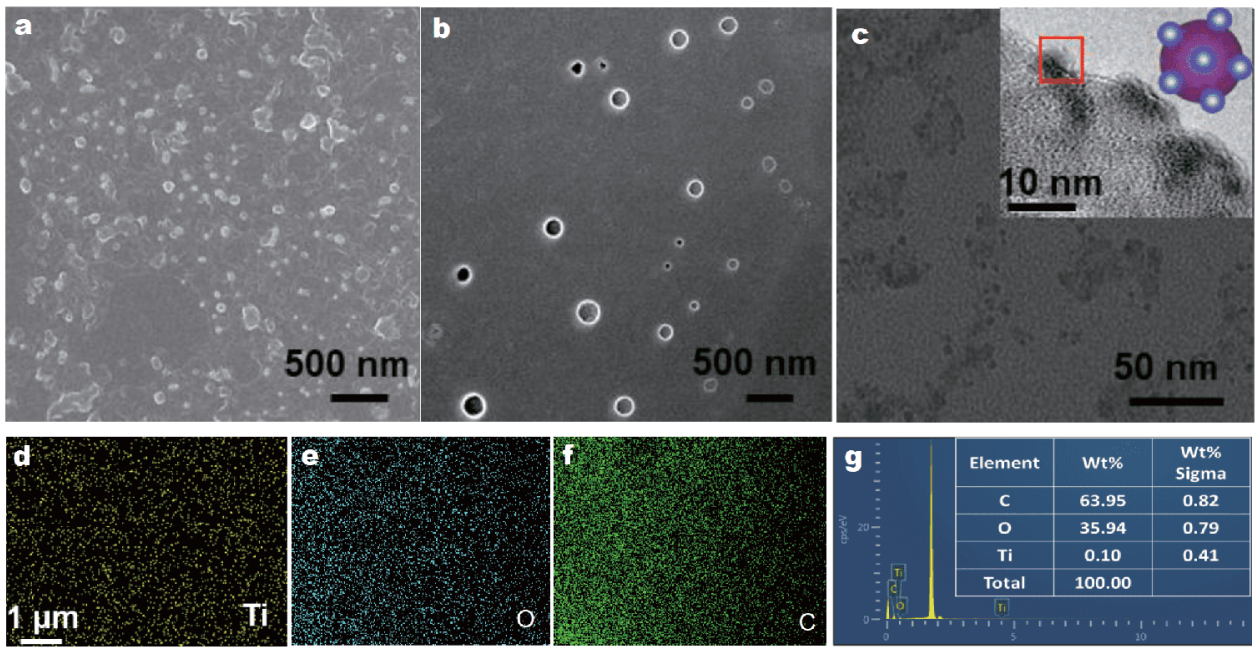

Figure 1 SEM images of $\mathrm{TiO}_{2} @$ glucose (a) and $\mathrm{TiO}_{2}-\mathrm{CQDs}$ (b); (c) TEM and HRTEM images of $\mathrm{TiO}_{2}-\mathrm{CQDs}$; (d-f) elemental analyses of TiO${ }_{2}-\mathrm{CQDs}$; (g) elemental analysis of $\mathrm{TiO}_{2}$-CQDs prepared by hydrothermal method. 


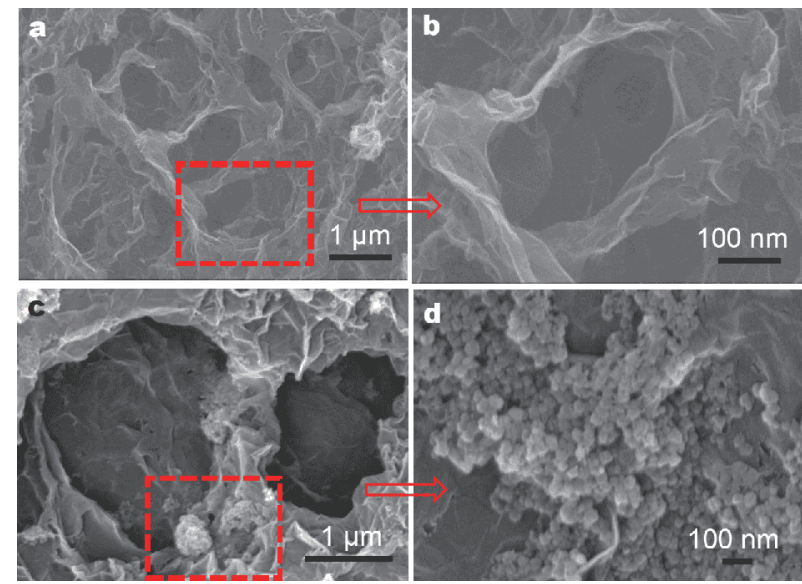

Figure 2 (a) SEM image of GO foam and (b) GO foam with larger magnification; (c) SEM image of $\mathrm{GO}-\mathrm{TiO}_{2}$-CQDs foam and (d) foam with larger magnification.

cribed to $n \rightarrow \sigma^{*}$, which can be observed in all three UVvis curves of CQDs, $\mathrm{TiO}_{2}$ and $\mathrm{TiO}_{2}-\mathrm{CQDs}$, verifying the existence of $-\mathrm{OH}$. When the composite nanoparticles form, the absorption peak slightly decreases relative to CQDs and $\mathrm{TiO}_{2}$, indicating the change of $-\mathrm{OH}$ content. Another peak, the $\mathrm{R}$ band, near $280 \mathrm{~nm}$ is ascribed to $\mathrm{n} \rightarrow \pi^{*}$, which can be seen in the UV-vis curves of CQDs and $\mathrm{TiO}_{2}$-CQDs. Due to the dehydration at high temperature, some oxygen functional groups of glucose and $-\mathrm{OH}$ on the surface of $\mathrm{TiO}_{2}$ powder turn into $\mathrm{C}=\mathrm{O}$. Besides, the inserted optical images of $\mathrm{TiO}_{2}$-CQDs under the natural light and the $365 \mathrm{~nm}$ ultraviolet light are also shown in Fig. 3a. As the specific color enhancement effect presents, the CQDs system is stabilized by the hybrid with $\mathrm{TiO}_{2}$. It can be observed that there is a slight blue fluorescence under $365 \mathrm{~nm}$ ultraviolet light.

Fig. $3 \mathrm{~b}$ shows the photoluminescence spectra of $\mathrm{TiO}_{2}$, CQDs and $\mathrm{TiO}_{2}-\mathrm{CQDs}$ nanoparticles. Due to the aggregation of hydroxyl groups on the surface of $\mathrm{TiO}_{2}$ in water, the most active emission wavelength of pure $\mathrm{TiO}_{2}$ is about $390 \mathrm{~nm}$ when the excitation wavelength is $260 \mathrm{~nm}$, while the most vigorous emissions of anatase and rutile locate at 378 and $400 \mathrm{~nm}$, respectively. For CQD and $\mathrm{TiO}_{2}-\mathrm{CQDs}$, by scanning the emission spectra at different excitation wavelengths, we can see that the most active excitation wavelength is about $340 \mathrm{~nm}$, and the corresponding emission wavelength is about $430 \mathrm{~nm}$. The anchoring of $\mathrm{TiO}_{2}$ results in the increase of fluorescence peak intensity at $430 \mathrm{~nm}$, indicating that the broadband gap of $\mathrm{TiO}_{2}$ affects the surface structure of CQDs, not the photoluminescence property. It can be assumed that, when the excitation light irradiates, a part of the electrons transfer to the CQDs, leading to the charge separation of the photogenerated electrons and holes in the $\mathrm{TiO}_{2}$. Generally, the band gap of $\mathrm{TiO}_{2}$ is about $3.0-3.2 \mathrm{eV}$, while the electron and hole easily recombine, limiting its application in catalysis. The CQDs, as a kind of photosensitive material, can effectively guide the electron transfer of $\mathrm{TiO}_{2}$, resulting in effective inhibition of electron and hole recombination. Therefore, electron and holes on the CQDs react with $\mathrm{O}_{2}$ and $\mathrm{H}_{2} \mathrm{O}$ to form superoxide anion $\left(\mathrm{O}_{2}{ }^{-}\right)$and hydroxyl radical $\left(\mathrm{HO}^{\circ}\right)$.

In Fig. 3c, the zeta potential of pure CQDs is unstable and displays a broad fluctuation range. Finally, it tends to stabilize at $-20 \mathrm{mV}$, where the CQDs are prone to aggregate. The pure $\mathrm{TiO}_{2}$ shows relatively stable zeta potential of $25 \mathrm{mV}$. While for $\mathrm{TiO}_{2}$-CQDs, the variation of zeta potential is within $40-80 \mathrm{mV}$ in steady state. The positive charge on the surface of $\mathrm{TiO}_{2}$-CQDs makes them easily assemble with GO. Fig. 3d shows the Raman spectra of the $\mathrm{TiO}_{2}$, CQDs, and $\mathrm{TiO}_{2}-\mathrm{CQD}$ s to elucidate the structural complexity of $\mathrm{TiO}_{2}$-CQDs, according to the separated peaks from different phases. The modes, $\mathrm{A}_{1 \mathrm{~g}}$ $\left(492 \mathrm{~cm}^{-1}\right), B_{1 \mathrm{~g}}\left(412\right.$ and $\left.492 \mathrm{~cm}^{-1}\right)$, and $\mathrm{E}_{\mathrm{g}}(144,209$, and $\left.630 \mathrm{~cm}^{-1}\right)$, are six fundamental transitions of anatase. The four modes, $A_{1 g}\left(614 \mathrm{~cm}^{-1}\right), \quad B_{1 g} \quad\left(143 \mathrm{~cm}^{-1}\right), \quad B_{2 g}$ $\left(822 \mathrm{~cm}^{-1}\right)$, and $\mathrm{E}_{\mathrm{g}}\left(432 \mathrm{~cm}^{-1}\right)$, are Raman-active modes of rutile. Therefore, the Raman spectra show the co-excitation of rutile and anatase $\mathrm{TiO}_{2}$ phases. The intensity of the observed peaks also indicates that the anatase is predominant.

The structural transitions of $\mathrm{GO}$ foam and $\mathrm{GO}-\mathrm{TiO}_{2}-$ CQDs foam are confirmed by FTIR, Raman, and XRD. As
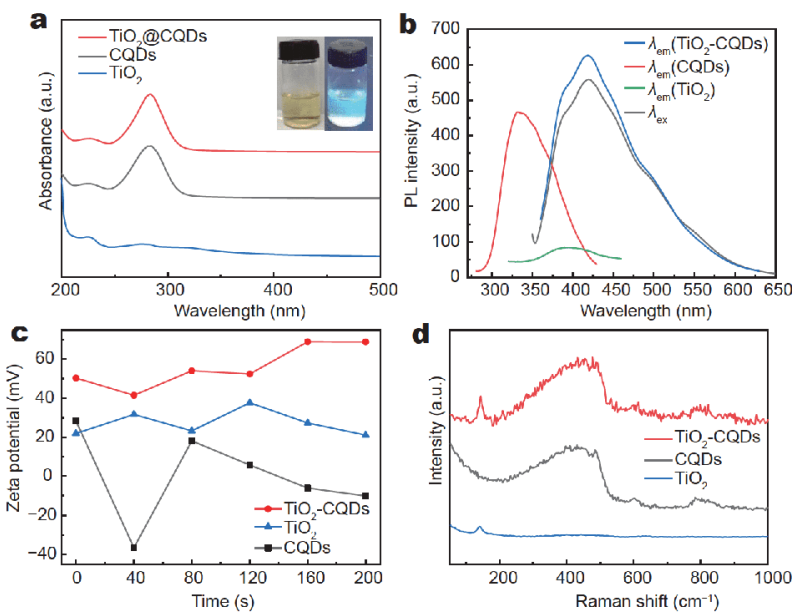

Figure 3 UV-vis spectra (a), fluorescence spectra (b), zeta potential (c) of $\mathrm{TiO}_{2}, \mathrm{CQDs}$ and $\mathrm{TiO}_{2}-\mathrm{CQDs}$, and Raman shift (d) of $\mathrm{TiO}_{2}, \mathrm{CQDs}$ and $\mathrm{TiO}_{2}$-CQDs. 
shown in Fig. 4a, FTIR spectra indicate that both the GO foam and $\mathrm{GO}-\mathrm{TiO}_{2}-\mathrm{CQD}$ s foam have some oxygencontaining groups, such as $-\mathrm{OH}\left(3446\right.$ and $\left.1442 \mathrm{~cm}^{-1}\right)$, $\mathrm{C}=\mathrm{O}\left(1639 \mathrm{~cm}^{-1}\right)$, and $\mathrm{C}-\mathrm{O}-\mathrm{C}\left(1110 \mathrm{~cm}^{-1}\right)$. Moreover, the peaks at 2850 and $2925 \mathrm{~cm}^{-1}$ correspond to $-\mathrm{CH}_{2}$ symmetry and antisymmetric stretching vibration. The vibrational peaks of the oxygen-containing functional groups are weakened, indicating that the high-temperature process results in the dehydration and reduction of the GO. Moreover, a typical skeletal vibration of Ti-O-Ti bonds near $522 \mathrm{~cm}^{-1}$ in $\mathrm{GO}-\mathrm{TiO}_{2}-\mathrm{CQD}$ foam can be observed, further confirming that $\mathrm{TiO}_{2}$ is chemically bonded to CQDs and GO, not only physical adsorption.

In the Raman spectra (Fig. $4 \mathrm{~b}$ ), the peaks of the D band at $1305 \mathrm{~cm}^{-1}$ and the $\mathrm{G}$ band at $1579 \mathrm{~cm}^{-1}$ are more obvious in $\mathrm{GO}-\mathrm{TiO}_{2}-\mathrm{CQDs}$ foam, indicating that the $\mathrm{GO}$ is stripped at high temperature and new defects introduced. The $I_{\mathrm{D}} / I_{\mathrm{G}}$ of GO foam increases from 1.10 to 1.23 for GO$\mathrm{TiO}_{2}$-CQDs foam, confirming the introduction of new defects in $\mathrm{GO}-\mathrm{TiO}_{2}-\mathrm{CQD}$ s foam. The other peaks at 599 and $590 \mathrm{~cm}^{-1}$ are ascribed to symmetric and antisymmetric expansion vibration of Ti-O. The peak at $807 \mathrm{~cm}^{-1}$ is ascribed to the lattice defects indicating the presence of $\mathrm{NH}_{3}$. The peak at $1061 \mathrm{~cm}^{-1}$ is ascribed to the antisymmetric stretching vibration of $-\mathrm{SO}_{3} \mathrm{H}$. Fig. $4 \mathrm{c}$ presents XRD patterns of the $\mathrm{GO}$ foam and $\mathrm{GO}-\mathrm{TiO}_{2}-\mathrm{CQD}$ foam. In the XRD pattern of $\mathrm{GO}-\mathrm{TiO}_{2}-\mathrm{CQDs}$ foam, the peaks at $2 \theta$ of $25.5^{\circ}, 37.2^{\circ}, 37.88^{\circ}, 48.14^{\circ}, 53.94^{\circ}, 55.14^{\circ}, 62.88^{\circ}$, $68.86^{\circ}, 70.36^{\circ}, 75.18^{\circ}$, and $82.86^{\circ}$ can be assigned to the (101), (103), (004), (200), (105), (211), (204), (116), (220), (215), and (224) of the anatase $\mathrm{TiO}_{2}$, respectively, in good agreement with the standard JCPDS card No. 028-1192.
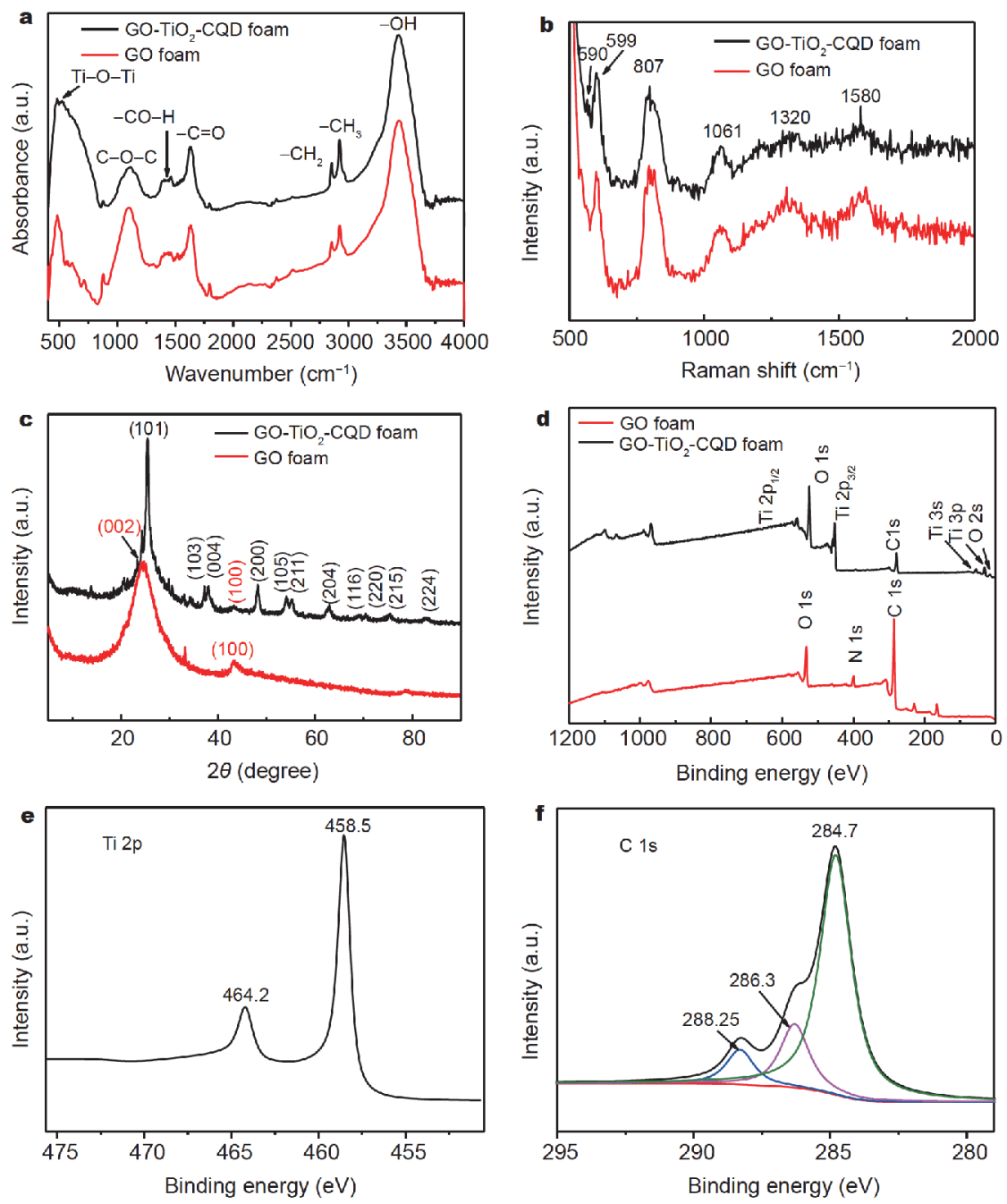

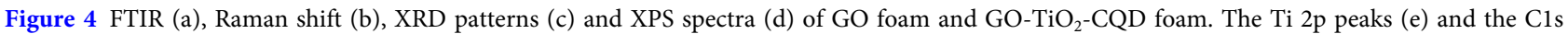
peaks (f) of $\mathrm{GO}-\mathrm{TiO}_{2}-\mathrm{CQD}$ foam. 
This proves that $\mathrm{TiO}_{2}$ in the $\mathrm{GO}-\mathrm{TiO}_{2}$-CQDs foam is mainly in the form of anatase. The typical (002) peak located at $24.6^{\circ}$ demonstrates the disorder stacking structure of GO layers. The weak broad (001) peak at $9.7^{\circ}$ implies the existence of a small amount of oxygen-containing groups.

From Fig. 4d, the XPS spectra of GO foam show bands located at 534, 400 and $285 \mathrm{eV}$, which are associated with the characteristic peak of $\mathrm{O} 1 \mathrm{~s}, \mathrm{~N} \mathrm{1s}$, and $\mathrm{C} 1 \mathrm{~s}$, respectively. The peak at about $400 \mathrm{eV}$ can be attributed to the formation of amino and amide groups due to the decomposition of thiourea. Meanwhile, the XPS spectrum of the synthesized $\mathrm{GO}-\mathrm{TiO}_{2}$-CQD foam shows three predominant binding energy peaks around 524, 453 and $278 \mathrm{eV}$, corresponding to the $\mathrm{C} 1 \mathrm{~s}$, Ti $2 \mathrm{p}$, and $\mathrm{O} 1 \mathrm{~s}$, respectively. As shown in Fig. 4e, the Ti $2 p$ spectrum shows two peaks at the binding energy of 464 and $459 \mathrm{eV}$, corresponding to $\mathrm{Ti} 2 \mathrm{p}_{3 / 2}$ and $\mathrm{Ti} 2 \mathrm{p}_{1 / 2}$, respectively [28]. The $\mathrm{C} 1 \mathrm{~s}$ spectrum in Fig. $4 \mathrm{f}$ consists of two binding energy peaks at 288 and $286 \mathrm{eV}$, assigned to the oxygen bound species $\mathrm{C}-\mathrm{O}$ and $\mathrm{C}=\mathrm{O}$, respectively. Another absolute peak at $284.7 \mathrm{eV}$ corresponds to the none-oxygenated ring $\mathrm{C}$ atom $(\mathrm{C}=\mathrm{C} / \mathrm{C}-\mathrm{C})$.

\section{Photocatalytic properties of the synthesized 3D foam for organic dyes}

The photocatalytic activities of the foam were investigated by adsorbing $\mathrm{MO}, \mathrm{RhB}$, and $\mathrm{MB}$. The photocatalytic degradations of $\mathrm{MO}$ over the $\mathrm{GO}$ foam, $\mathrm{GO}-\mathrm{TiO}_{2}$ foam, and GO- $\mathrm{TiO}_{2}-\mathrm{CQDs}$ foam were detected by UV-vis spectroscopy. MO displays orange color in water and absorbs in the visible region at $466 \mathrm{~nm}$. Based on the Lambert-Bill law, a linear relationship between the absorbance and the concentration of the dye solution is assumed. Here, the photocatalytic degradation rate $(D \%)$ is defined as the following formula [34]:

$D \%=\frac{\left(A_{0}-A_{T}\right) \times 100 \%}{A_{0}}$.

Therein, $A_{0}$ is the absorbance of the original solution, and $A_{T}$ is the absorbance at $T$ min. Fig. $5 \mathrm{a}-\mathrm{c}$ show the time-dependent $\mathrm{UV}$-vis spectra of $\mathrm{MO}$ in the presence of the GO foam, $\mathrm{GO}-\mathrm{TiO}_{2}$ foam and $\mathrm{GO}-\mathrm{TiO}_{2}$-CQDs foam in a neutral aqueous solution under Xenon lamp irradiation. The absorbance intensity of MO gradually decreases as a function of time under irradiation. As shown in Fig. 5d, the corresponding degradation efficiencies for GO foam, GO- $\mathrm{TiO}_{2}$ foam, GO-TiO ${ }_{2}$-CQDs foam, and $\mathrm{TiO}_{2}$ powder are about $68.37 \%, 81.57 \%, 92.47 \%$, and $13.85 \%$, respectively. The faster and higher degradation of $\mathrm{MO}$ was observed in the presence of the $\mathrm{GO}-\mathrm{TiO}_{2}$-CQDs foam. After $3 \mathrm{~h}$, the color of aqueous MO solution with GO- $\mathrm{TiO}_{2}$-CQDs foam almost disappears (Fig. $5 \mathrm{c}$ inset). This phenomenon indicates that not only the GO foam, but also the $\mathrm{TiO}_{2}$-CQDs nanoparticles have specific catalytic degradation effect on dyes.

Also, the degradation experiments were carried out on $\mathrm{RhB}$ and $\mathrm{MB}$ with $\mathrm{GO}$ foam, $\mathrm{GO}-\mathrm{TiO}_{2}$ foam, and GO$\mathrm{TiO}_{2}$-CQDs foam. The time-dependent degradation curves are shown in Fig. 5e. The $\mathrm{GO}-\mathrm{TiO}_{2}-\mathrm{CQD}$ foam displays a stronger degradation rate $(95.54 \%)$ to $\mathrm{MB}$ than GO- $\mathrm{TiO}_{2}$ foam (85.46\%), GO foam (81.95\%) and $\mathrm{TiO}_{2}$ powder (30.99\%). Similar to $\mathrm{MO}$ and $\mathrm{MB}$, when GO foam, $\mathrm{GO}-\mathrm{TiO}_{2}$ foam, and $\mathrm{TiO}_{2}$ powder were added to $\mathrm{RhB}$ solution, the degradation efficiencies were $68.41 \%$, $75.96 \%$, and $25.50 \%$. However, when $\mathrm{GO}-\mathrm{TiO}_{2}-\mathrm{CQDs}$ foam was added, the degradation efficiency was increased to $92.84 \%$ (Fig. 5f). The slope of the photocatalysis degradation kinetic curve illustrates that the $\mathrm{GO}-\mathrm{TiO}_{2}$ CQDs foam has a faster degradation rate and higher degradation efficiency towards MB (Fig. 5d-f), which may be attributed to the stronger electrostatic adsorption effects aroused by the more considerable negative surface potential of $\mathrm{MB}$. The recycling degradation experiments using $\mathrm{GO}$ foam, $\mathrm{GO}-\mathrm{TiO}_{2}$ foam, and $\mathrm{GO}-\mathrm{TiO}_{2}-\mathrm{CQDs}$ foam were performed under the same conditions. As shown in Fig. 5g-i, the degradation efficiencies of MB, $\mathrm{MO}$, and $\mathrm{RhB}$ all maintain at a high level for GO foam, GO- $\mathrm{TiO}_{2}$ foam, and $\mathrm{GO}-\mathrm{TiO}_{2}$-CQDs foam.

Combined with the explanation of photocatalytic effect in the previous work $[22,35]$, the photocatalytic elucidation of the $\mathrm{GO}-\mathrm{TiO}_{2}-\mathrm{CQDs}$ foam is schematically shown in Scheme 2. Pairs of electrons and holes are produced when photocatalyst $\mathrm{TiO}_{2}$ nanoparticles absorb UV radiation from Xenon lamp. As the results of FL-testing show, the combination of $\mathrm{TiO}_{2}$ and CQDs can effectively transfer the photogenerated electrons generated by $\mathrm{TiO}_{2}$ to the surface of carbon dots. In detail, parts of negativeelectrons $\left(\mathrm{e}^{-}\right)$are easily transferred to CQDs, and the other parts of negative-electrons ( $\mathrm{e}^{-}$) transfer to GO. Thereby, the lifetime of photogenerated electrons is increased, and the photocatalytic effect is improved.

Moreover, these electrons react with oxygen in the water to form superoxide anion $\left(\mathrm{O}_{2}{ }^{-}\right)$for further oxidizing dyes. On the other hand, the positive-holes $\left(\mathrm{h}^{+}\right)$left behind by the electron transfer on $\mathrm{TiO}_{2}$ will react with water to form hydroxyl radicals $\left(\mathrm{OH}^{*}\right)$. The hydroxyl radicals can oxidize dyes and finally mineralize them into the water and harmless inorganics. Interestingly, by transferring electrons out of $\mathrm{TiO}_{2}$ to GO or CQDs, the combination of negative-electrons $\left(\mathrm{e}^{-}\right)$and the positive- 

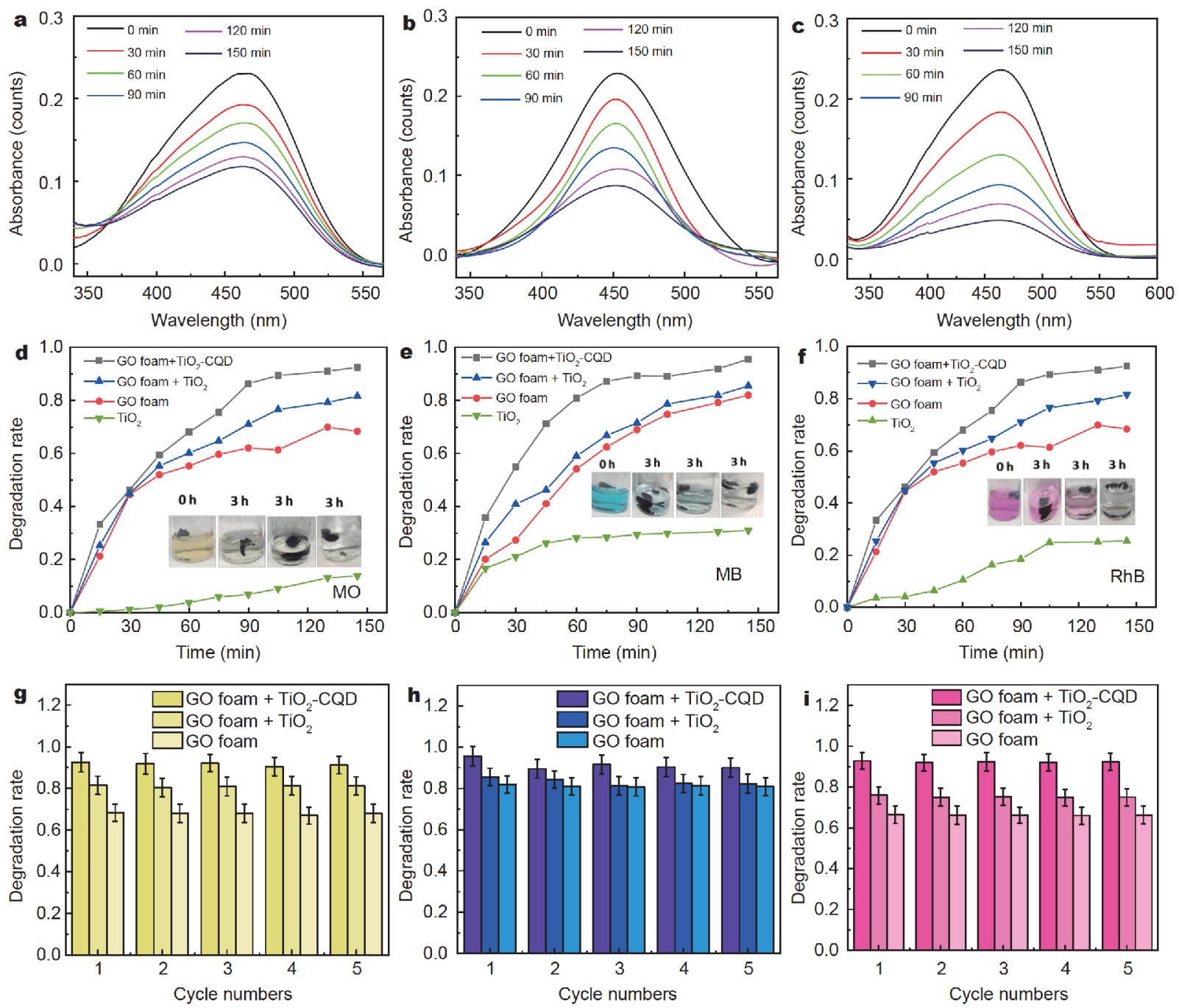

Figure 5 UV-vis spectra of $\mathrm{MO}$ degradation with GO foam (a), GO- $\mathrm{TiO}_{2}$ foam (b) and $\mathrm{GO}-\mathrm{TiO}_{2}-\mathrm{CQDs}$ foam (c) with different irradiation times; photocatalytic degradation kinetics of $\mathrm{MO}(\mathrm{d}), \mathrm{MB}(\mathrm{e}), \mathrm{RhB}(\mathrm{f})$ and the relevant optical image of the degradation with $\mathrm{GO}$ foam, $\mathrm{GO}-\mathrm{TiO}{ }_{2}$ foam, GO$\mathrm{TiO}_{2}$-CQD foam and $\mathrm{TiO}_{2}$ powder after $3 \mathrm{~h}$; the error for each data point is not more than $5 \%$, photocatalysis degradation rates of $\mathrm{MO}$ (g), $\mathrm{MB}$ (h) and $\mathrm{RhB}(\mathrm{i})$ at different cycles.

hole $\left(\mathrm{h}^{+}\right)$could effectively improve the photocatalytic efficiency of $\mathrm{GO}-\mathrm{TiO}_{2}$-CQDs foam. Compared with the previous reported $\mathrm{TiO}_{2}$ nanoparticles only combined with GO or CQD, this $3 \mathrm{D}$ foam can more effectively improve the transfer rate of photogenerated electrons and promote the separation of electrons and holes to improve the photocatalytic effect.

\section{CONCLUSIONS}

In summary, a novel photoactive $\mathrm{GO}-\mathrm{TiO}_{2}-\mathrm{CQDs}$ composite, consisting of GO, CQD, and $\mathrm{TiO}_{2}$, was fabricated via a facile and efficient solvothermal route. This GO$\mathrm{TiO}_{2}$-CQDs composite displays a 3D foam structure, in which $\mathrm{TiO}_{2}$-CQDs microspheres adsorb on porous graphene sheets. Compared with pure GO foam, the fabricated $\mathrm{GO}-\mathrm{TiO}_{2}-\mathrm{CQD}$ foam displays high degradation rates of $92.48 \%, 95.54 \%$, and $92.84 \%$ towards $\mathrm{MO}, \mathrm{MB}$, and $\mathrm{RhB}$, respectively, under the Xenon lamp irradiation. This indicates that the high degradation efficiency benefits from the GO sheets, which can accept electrons and inhibit charge recombination between the electrons in the conduction band of $\mathrm{TiO}_{2}$ and holes in the valence band of CQDs. Besides, $\mathrm{GO}^{-\mathrm{TiO}_{2}}$-CQDs foam maintains the high photodegradation rate after being used for several times, indicating the remarkable degradation capability and stability. The encouraging performances indicate that the 


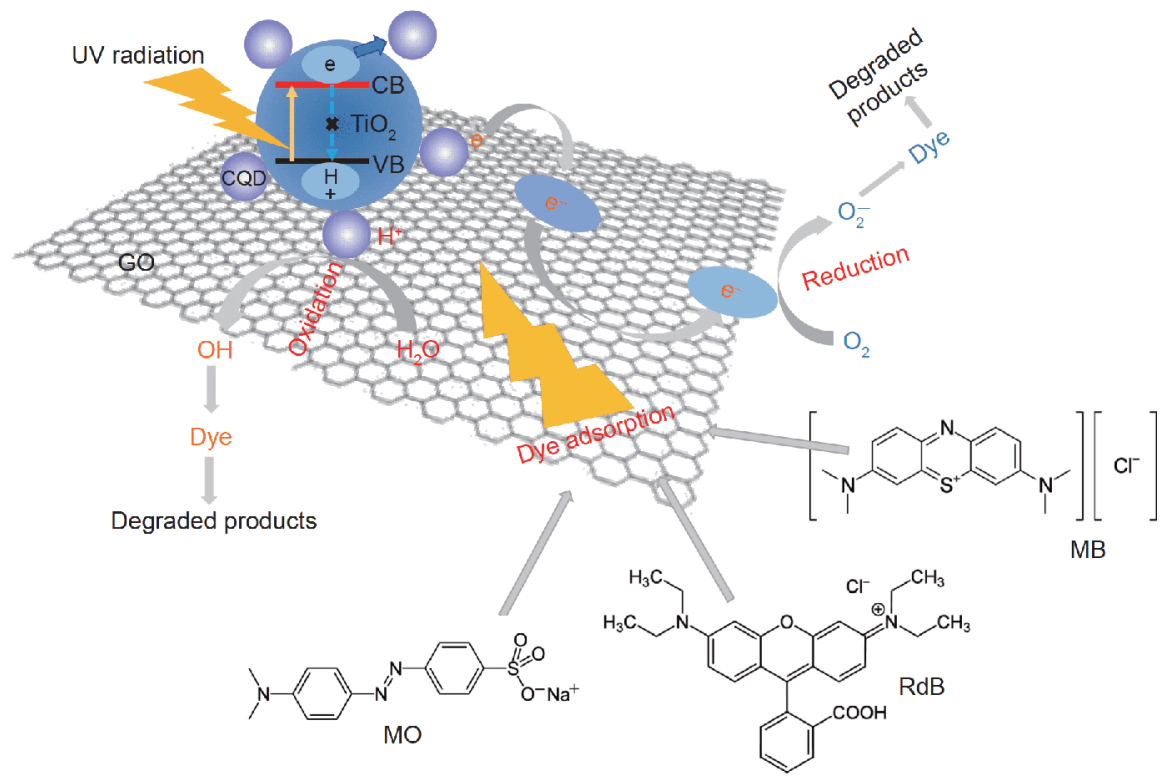

Scheme 2 Photocatalytic degradation mechanism of the synthesized $\mathrm{GO}-\mathrm{TiO}_{2}$-CQDs foam on organic dyes under Xenon lamp irradiation.

obtained $\mathrm{GO}-\mathrm{TiO}_{2}-\mathrm{CQDs}$ foam may have a promising prospect as photocatalyst. More broadly, our 3D foam provides photogenerated electrons with strong reduction ability and photoelectron with strong reduction ability under Xenon lamp. Therefore, this 3D platform is expected to be used for the preparation of hydrogen by high efficient photolysis of water.

Received 1 June 2019; accepted 7 July 2019;

published online 31 July 2019

1 Liu W, Liu Z, Wang G, et al. Carbon coated $\mathrm{Au} / \mathrm{TiO}_{2}$ mesoporous microspheres: A novel selective photocatalyst. Sci China Mater, 2017, 60: 438-448

2 Yang $\mathrm{X}$, Tian L, Zhao X, et al. Interfacial optimization of $\mathrm{g}-\mathrm{C}_{3} \mathrm{~N}_{4}-$ based Z-scheme heterojunction toward synergistic enhancement of solar-driven photocatalytic oxygen evolution. Appl Catal B-Environ, 2019, 244: 240-249

3 Pacholski C, Kornowski A, Weller H. Site-specific photodeposition of silver on $\mathrm{ZnO}$ nanorods. Angew Chem Int Ed, 2004, 43: 47744777

4 Ding J, Zhu S, Zhu T, et al. Hydrothermal synthesis of zinc oxidereduced graphene oxide nanocomposites for an electrochemical hydrazine sensor. RSC Adv, 2015, 5: 22935-22942

5 Sun K, Wang L, Wu C, et al. Fabrication of $\alpha-\mathrm{Fe}_{2} \mathrm{O}_{3} @ \mathrm{rGO} / \mathrm{PAN}$ nanofiber composite membrane for photocatalytic degradation of organic dyes. Adv Mater Interfaces, 2017, 4: 1700845

6 Tian J, Zhao Z, Kumar A, et al. Recent progress in design, synthesis, and applications of one-dimensional $\mathrm{TiO}_{2}$ nanostructured surface heterostructures: A review. Chem Soc Rev, 2014, 43: 6920-6937

7 Almeida BM, Melo Jr. MA, Bettini J, et al. A novel nanocomposite based on $\mathrm{TiO}_{2} / \mathrm{Cu}_{2} \mathrm{O} /$ reduced graphene oxide with enhanced solar- light-driven photocatalytic activity. Appl Surf Sci, 2015, 324: 419431

8 Ding J, Sun W, Wei G, et al. Cuprous oxide microspheres on graphene nanosheets: An enhanced material for non-enzymatic electrochemical detection of $\mathrm{H}_{2} \mathrm{O}_{2}$ and glucose. RSC Adv, 2015, 5: 35338-35345

9 Zhao X, Li Y, Guo Y, et al. Coral-like $\mathrm{MoS}_{2} / \mathrm{Cu}_{2} \mathrm{O}$ porous nanohybrid with dual-electrocatalyst performances. Adv Mater Interfaces, 2016, 3: 1600658

10 Gao C, Li X, Lu B, et al. A facile method to prepare $\mathrm{SnO}_{2}$ nanotubes for use in efficient $\mathrm{SnO}_{2}-\mathrm{TiO}_{2}$ core-shell dye-sensitized solar cells. Nanoscale, 2012, 4: 3475-3481

11 Cui S, Wen Z, Huang X, et al. Stabilizing $\mathrm{MoS}_{2}$ nanosheets through $\mathrm{SnO}_{2}$ nanocrystal decoration for high-performance gas sensing in air. Small, 2015, 11: 2305-2313

$12 \mathrm{Yu} \mathrm{X}$, Lin D, Li P, et al. Recent advances in the synthesis and energy applications of $\mathrm{TiO}_{2}$-graphene nanohybrids. Sol Energy Mater Sol Cells, 2017, 172: 252-269

13 Dong X, Cao Y, Wang J, et al. Hybrid structure of zinc oxide nanorods and three dimensional graphene foam for supercapacitor and electrochemical sensor applications. RSC Adv, 2012, 2: 43644369

14 Zhang Y, Tang ZR, Fu X, et al. Engineering the unique 2D mat of graphene to achieve graphene- $\mathrm{TiO}_{2}$ nanocomposite for photocatalytic selective transformation: What advantage does graphene have over its forebear carbon nanotube? ACS Nano, 2011, 5: 74267435

15 Zhang L, Hu X, Wang C, et al. Water-dispersible and recyclable magnetic $\mathrm{TiO}_{2}$ /graphene nanocomposites in wastewater treatment. Mater Lett, 2018, 231: 80-83

16 Shirai K, Fazio G, Sugimoto T, et al. Water-assisted hole trapping at the highly curved surface of nano- $\mathrm{TiO}_{2}$ photocatalyst. J Am Chem Soc, 2018, 140: 1415-1422

17 Razali MH, Yusoff M. Highly efficient $\mathrm{CuO}$ loaded $\mathrm{TiO}_{2}$ nanotube 
photocatalyst for $\mathrm{CO}_{2}$ photoconversion. Mater Lett, 2018, 221: 168-171

18 Pan $\mathrm{X}$, Zhao $\mathrm{Y}$, Liu S, et al. Comparing graphene- $\mathrm{TiO}_{2}$ nanowire and graphene- $\mathrm{TiO}_{2}$ nanoparticle composite photocatalysts. ACS Appl Mater Interfaces, 2012, 4: 3944-3950

19 Wang C, Zhang X, Zhang Y, et al. Hydrothermal growth of layered titanate nanosheet arrays on titanium foil and their topotactic transformation to heterostructured $\mathrm{TiO}_{2}$ photocatalysts. J Phys Chem C, 2011, 115: 22276-22285

20 Li B, Xi B, Feng Z, et al. Hierarchical porous nanosheets constructed by graphene-coated, interconnected $\mathrm{TiO}_{2}$ nanoparticles for ultrafast sodium storage. Adv Mater, 2018, 30: 1705788

21 Quan Q, Xie S, Weng B, et al. Revealing the double-edged sword role of graphene on boosted charge transfer versus active site control in $\mathrm{TiO}_{2}$ nanotube arrays@RGO/MoS${ }_{2}$ heterostructure. Small, 2018, 14: 1704531

22 Sathish Kumar M, Yamini Yasoda K, Kumaresan D, et al. $\mathrm{TiO}_{2}^{-}$ carbon quantum dots (CQD) nanohybrid: Enhanced photocatalytic activity. Mater Res Express, 2018, 5: 075502

23 Yang J, Wen Z, Shen X, et al. A comparative study on the photocatalytic behavior of graphene- $\mathrm{TiO}_{2}$ nanostructures: Effect of $\mathrm{TiO}_{2}$ dimensionality on interfacial charge transfer. Chem Eng J, 2018, 334: $907-921$

24 Chen W, Li S, Chen C, et al. Self-assembly and embedding of nanoparticles by in situ reduced graphene for preparation of a 3D graphene/nanoparticle aerogel. Adv Mater, 2011, 23: 5679-5683

25 Long R, Casanova D, Fang WH, et al. Donor-acceptor interaction determines the mechanism of photoinduced electron injection from graphene quantum dots into $\mathrm{TiO}_{2}: \pi$-Stacking supersedes covalent bonding. J Am Chem Soc, 2017, 139: 2619-2629

26 Zhang Y, Foster CW, Banks CE, et al. Graphene-rich wrapped petal-like rutile $\mathrm{TiO}_{2}$ tuned by carbon dots for high-performance sodium storage. Adv Mater, 2016, 28: 9391-9399

27 Lee JS, You KH, Park CB. Highly photoactive, low bandgap $\mathrm{TiO}_{2}$ nanoparticles wrapped by graphene. Adv Mater, 2012, 24: 10841088

28 Yu X, Liu W, Deng X, et al. Gold nanocluster embedded bovine serum albumin nanofibers-graphene hybrid membranes for the efficient detection and separation of mercury ion. Chem Eng J, 2018, 335: 176-184

29 Yu X, Zhang W, Zhang P, et al. Fabrication technologies and sensing applications of graphene-based composite films: Advances and challenges. Biosens Bioelectron, 2017, 89: 72-84

30 Kim H, Cho MY, Kim MH, et al. A novel high-energy hybrid supercapacitor with an anatase $\mathrm{TiO}_{2}$-reduced graphene oxide anode and an activated carbon cathode. Adv Energy Mater, 2013, 3: 1500-1506

31 Deng W, Fang Q, Zhou X, et al. Hydrothermal self-assembly of graphene foams with controllable pore size. RSC Adv, 2016, 6: 20843-20849

32 Li K, Liu W, Ni Y, et al. Technical synthesis and biomedical applications of graphene quantum dots. J Mater Chem B, 2017, 5: 4811-4826

33 Marcano DC, Kosynkin DV, Berlin JM, et al. Improved synthesis of graphene oxide. ACS Nano, 2010, 4: 4806-4814

34 Sakthivel S, Neppolian B, Shankar MV, et al. Solar photocatalytic degradation of azo dye: Comparison of photocatalytic efficiency of $\mathrm{ZnO}$ and $\mathrm{TiO}_{2}$. Sol Energy Mater Sol Cells, 2003, 77: 65-82

35 Atchudan R, Jebakumar Immanuel Edison TN, Perumal S, et al. Effective photocatalytic degradation of anthropogenic dyes using graphene oxide grafting titanium dioxide nanoparticles under UVlight irradiation. J PhotoChem PhotoBiol A-Chem, 2017, 333: 92104

Acknowledgements This work was supported by the National Natural Science Foundation of China (NSFC, 51573013 and 51873016) and the Open Project Program of Beijing Key Laboratory of Quality Evaluation Technology for Hygiene and Safety of Plastics, Beijing Technology and Business University (QETHSP2019006).

Author contributions Zhang $\mathrm{X}$, Wen $\mathrm{B}$, and Su Z designed the project; Wei $\mathrm{W}$, Zhang $\mathrm{X}$, and Zhang $\mathrm{S}$ performed the experiments; Zhang $\mathrm{X}$ and Wei W wrote the paper with support from Wen B and Su Z. All authors contributed to the general discussion.

Conflict of interest The authors declare no conflict of interest.

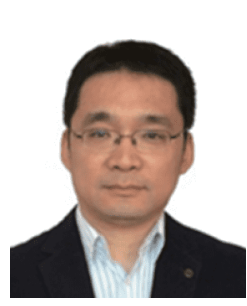

Zhiqiang Su was born in 1975 and obtained his $\mathrm{PhD}$ degree in 2005 at the Institute of Chemistry, Chinese Academy of Sciences. After a postdoctoral stay at Tsinghua University, he joined Beijing University of Chemical Technology in 2007 and was appointed as full professor in 2012. In 2011 he worked at Friedrich-Schiller-University Jena, Germany as an experienced research fellow of Alexander von Humboldt Foundation. His research interest includes nanohybrids, biomedical materials, biosensors, and bioelectronics. So far, he has published more than 100 peer-reviewed papers with 3300 citations. His H-index is 35 .

\section{氧化石墨烯基3D泡沫的制备策略、界面协同机理 和高效光催化性能研究}

张晓媛 ${ }^{1 \dagger}$, 魏文锋 $^{1 \dagger}$, 张山 $^{1}$, 温变英 ${ }^{2 *}$, 苏志强 ${ }^{{ }^{*}}$

摘要 本文通过高效低成本的水热法将 $\mathrm{TiO}_{2} @ \mathrm{CQD}$ s插入还原氧化 石墨烯片层间, 制备了一种独特的纳米杂化三维 $\mathrm{rGO}-\mathrm{TiO}_{2}-\mathrm{CQDs}$ 泡沫. 在氙灯照射下, 所合成的三维 $\mathrm{rGO}-\mathrm{TiO}_{2}-\mathrm{CQD}$ s泡沫对甲基橙 $(\mathrm{MO})$ 、亚甲蓝 $(\mathrm{MB})$ 以及罗丹明 $\mathrm{B}(\mathrm{RhB})$ 表现出很高的降解速率, 在 多次使用后仍然保持高效且形貌不变. 这种优异的光催化性能归 因于rGO- $\mathrm{TiO}_{2}-\mathrm{CQD}$ 泡沫的多孔结构, 以及密集吸附在石墨烯表 面上的催化剂 $\mathrm{TiO}_{2} @ \mathrm{CQD}$ s. 本文中所描述的三维杂化泡沫将光催 化剂 $\mathrm{TiO}_{2}$ 与半导体石墨烯和碳量子点结合, 有望为进一步提高电 荷分离效率, 进而提高光催化效果, 开辟一条新途径. 